The Geneva Papers on Risk and Insurance, 21 (No. 79, April 1996), 240-257

\title{
Optimal Liability: The Effects of Risk Aversion, Loaded Insurance Premiums, and the Number of Victims*
}

\author{
by Martin Nell** and Andreas Richter**
}

\section{Introduction}

The economic analysis of liability law has been established as a field of intensive research during the last decades. Starting with Calabresi (1961) and Brown (1973), many articles dealt with the problem of optimal liability rules, among others Shavell (1980), (1982), (1987), Adams (1985) and Endres (1991). Surprisingly most of the research concentrates on incentive problems of liability law only, by investigating which liability rules can induce injurers and victims to choose the optimal level of care. Little attention was directed at the distributional consequences of liability and their efficiency implications. Especially the risk allocation function of liability law has been neglected in much of the literature, although incentive compatibility and optimal risk allocation are equally important and interdependent objectives in economic theory.

Two alternative assumptions made it possible to neglect the risk allocation aspects of liability law:

- In standard theory all economic actors are assumed to be risk neutral.

- If authors deal with risk averse economic actors, it is often assumed that insurance coverage is available at a fair premium. Since in that case the risk can be transferred to insurance companies without any cost, risk aversion doesn't matter for liability rules.

\footnotetext{
* The authors would like to thank Dorothea Alcwell. Dieter Hesberg, Walter Karten. Petra Lenz, and the participants of the 6th Joint Conference between the European Association of Law and Economics and the Geneva Association in Yvoire (France). especially James Boyd and Göran Skogh, for valuable comments. The usual disclaimer applies.

** Universität Hamburg, Institut für Versicherungsbetricbslehre, Von-Mellc-Park 5, 20146 Hamburg, Germany.
} 
Discussing the first assumption, one should distinguish between the risk attitudes of individuals and firms: While it is widely accepted that individuals behave risk averse, the assumption most often used concerning the risk attitudes of firms is risk neutral behavior. The main argument for the latter assumption is that the shareholders hold well-diversified portfolios and will thus aim at maximizing the expected profit of the firm (see for example Shavell (1987), p. 189, and Milgrom/Roberts (1992), p. 187). It follows immediately that this explanation is only valid for joint stock companies, but not for partnerships.

There is another argument for the limited validity of the risk neutrality assumption: Entrepreneurial decisions are made by management, but not by the shareholders, for whom it is normally impossible to control all those decisions. Management thus has a certain discretion in activity on the firms' behalf. It is a standard result of agency theory that management's income should depend on the firms' profit in order to give appropriate incentives (see among others Tirole (1990), p. 29). The individual manager cannot perfectly diversify his profit dependent income. Thus some of the most influential decision makers will exhibit risk aversion, at least if they are confronted with the possibility of large losses. Hence, even for joint stock companies, under realistic assumptions concerning the imperfect management-shareholder relationship and the resulting incentive problems risk aversion in firm behavior is a very plausible assumption. This premise has empirical support as joint stock companies buy insurance coverage at a substantial extent (see Tillinghast (1990)), which is most easily explained by risk aversion. ${ }^{1}$ Therefore in the following we will assume that all economic actors are risk averters.

Turning to the second assumption one can see that in reality insurance coverage is not available at fair premiums. There are a number of different reasons for this, but it is sufficient to assume transaction costs to substantiate a loading on the expected value of losses. In Germany for example more than 300.000 employees are working in the insurance industry. How could all these people get paid if insurance premiums were fair?

As both assumptions are rather unrealistic, the analysis of liability law can be strongly improved by including the aspect of risk allocation, which is influenced by the price for insurance coverage: The risk allocation aspect becomes the less important the smaller the loading is. Therefore, insurance has to be included into the analysis. We present a model which helps us to determine simultaneously the demand for insurance coverage, the level of care and optimal liability. It is an extension of a model presented by Traub/Nell (1993) and Nell/Traub (1994), which analyses optimal liability rules for insurance brokers in the case of risk aversion but without liability insurance.

We assume complete information of the insurer and do not consider any moral hazard problems, as our main interest is the analysis of risk allocation. Moral hazard problems have been treated in some papers, for example by Shavell (1982) and Endres (1991), who mainly discuss the question whether liability insurance with incomplete information of the insurer is socially desirable. Under our assumption of complete information no moral hazard problems occur. We can therefore concentrate on the determination of optimal liability rules in a situation where the supply of insurance contracts is exogenously given.

Grace/Rebello (1993) explain corporate insurance demand alternatively as a signaling behavior. But for deriving their results they need the assumption of fair insurance premiums. 
The most features of the model apply to general analysis of liability problems. But we consider one aspect that seems to be important for particular areas of liability law: Analysing e.g. environmental liability problems, one is often faced with situations where one injurer causes losses to many victims. In the standard theory of liability law, this situation corresponds exactly to the one injurer- one victim-case. But if risk aversion is taken into account, we get important modifications of the results, because the risk premium of the injurer increases strongly with the number of potential victims.

The topic of this paper is related to the subject of a recent article by Arlen (1992), but there are important differences in the treatment of risk aversion: Arlen argues that wealth differences between risk averse individuals have an impact on optimal liability rules even if insurance is available at fair premiums. Since risk aversion implies a decreasing marginal utility of wealth, the negative utility impact of a given amount of money which is invested in care activities decreases with increasing wealth. Therefore, c.p. the costs of care decrease with increasing wealth. As Green (1976) has shown, such differences in the costs of care have to be taken into consideration for the determination of optimal liability rules: The larger the wealth of the injurer, the higher the optimal standard of due care under the negligence rule and the higher the optimal damage award under a strict liability rule.

Arlen assumes fair insurance premiums. This implies the costless transfer of risk to insurance companies. Thus the importance of risk aversion in Arlen's paper lies solely in the decreasing marginal utility of wealth. In contrast to Arlen, we use the assumption that as in reality - a loading on insurance premiums exists. Thus risk bearing is no longer costless and the risk allocation aspects have to be taken into account for the determination of optimal liability rules. As we concentrate on risk allocation aspects, differences in the costs of care between individuals are not analysed in our paper. Both aspects, wealth differences and loadings on insurance premiums, are without any doubt very realistic assumptions. Thus both papers demonstrate that the prevailing opinion, according to which risk aversion is irrelevant for the determination of optimal liability rules, cannot be maintained under realistic conditions. However, they do so by different arguments, and it is an important task for future research to integrate both arguments into one model.

Furthermore, basic concepts of the paper are related to agency theory, as risk allocation and incentive structures of liability rules are analysed. The focus of agency theory is on the effects of incomplete and asymmetric information about the agent's behavior. These effects are conceptualized by comparing a First-Best-Optimum (FBO), which refers to situations under complete information, to a Second-Best-Optimum (SBO), which refers to situations with asymmetric information, where the principal has no information about the agent's behavior, but only about the resulting output, which is assumed to depend on the agent's activity level and a random variable. Under complete information in the FBO, the principal can apply contracts which specify the optimal activity level of the agent as well as optimal risk sharing. This first best contract, which cannot be realized under incomplete information, is then used as a point of reference for the second best contract, which can only specify the agent's share in the risky output. The determination of the output dependent wage thus has two functions: it controls the risk allocation between principal and agent as well as the agent's activity level. As there is only one «instrument» to handle two conflicting goals, the second best contract implies an «optimal compromise» between incentive and risk allocation aspects. 
For our analysis of liability rules, we apply the same basic structure: The two instruments which could be used to control incentives and risk allocation are the determination of due care and of a share in liability. The FBO refers to a situation, where both instruments can be used to optimize the risk allocation and the level of care simultaneously. The SBO refers to a situation where no standard of due care is established. In this situation the injurer's share in liability controls risk allocation as well as the level of care. Thus, only a compromise between the two conflicting goals can be achieved.

In contrast to agency theory, where the FBO is only a point of reference, which can never be realized under the assumption of asymmetric information, in our analysis of optimal liability the FBO refers to situations in which courts are able to determine a standard of due care besides the share in liability.

The remainder of the paper is organized as follows. Section 2 contains a description of the model. In section 3, we examine optimal solutions for a situation without insurance. The case where the injurer can buy liability insurance is considered in section 4 . In both sections the analysis begins with the determination of the FBO and goes on with the analysis of the SBO. The final section presents a summary of the results and a discussion of some possible modifications of the model.

\section{The model}

We assume that the potential injurer engages in some activity, for example the production of certain goods, which allows him to earn a certain utility expressed as a monetary equivalent $N .^{2}$ The activity involves the risk of harming other persons, the potential victims. Let $n$ be the number of victims, who are assumed to be identical for simplicity. ${ }^{3}$ They have identical preferences and the losses are identically distributed and totally correlated. Standard models assume that there is only one victim, $n=1$. To demonstrate the important influence the number of victims has on the optimality of liability rules, the effect of an increasing $n$ will be examined.

The single victim's losses are expressed by a random variable $L$, which depends on the injurer's level of care $x(0 \leq x)$ and a random variable $Y(L=L(x, Y))$. There shall be an upper boundary to the level of care, $x_{\max }$. As an example consider the installation of the most effective filtration plant to avoid harmful emissions or the carrying-out of all thinkable testing procedures before introducing a new pharmaceutical product. We deal with unilateral losses only, which means that the potential victims cannot influence the risk of being injured by taking care. This assumption seems quite realistic e.g. for environmental risks and many aspects of product liability.

For each level of care $x$ the expected value and the variance of losses shall have the following properties: ${ }^{4}$

${ }^{2}$ Note that we consider this monetary equivalent and therefore the injurer's output as given.

${ }^{3}$ We deal with a fixed number of potential victims, which means that in the case of, for example, an emission all potential victims would suffer. Surely in a more realistic but also much more complicated model the number of victims has to be a random variable.

${ }^{4} \mathrm{It}$ is assumed that there are no problems of differentiability. 


$$
\begin{aligned}
& E[L(x, Y)]_{x}<0, E[L(x, Y)]_{x x} \geq 0 \\
& \sigma^{2}[L(x, Y)]_{x}<0, \sigma^{2}[L(x, Y)]_{x x} \geq 0 \\
& 0<E\left[L\left(x_{\max }, Y\right)\right] \leq E[L(x, Y)] \leq E[L(0, Y)]<\infty \\
& 0<\sigma^{2}\left[L\left(x_{\max }, Y\right)\right] \leq \sigma^{2}[L(x, Y)] \leq \sigma^{2}[L(0, Y)]<\infty
\end{aligned}
$$

There are upper boundaries to the expected value and the variance of losses, which apply if the injurer decides not to take care at all. Both parameters of risk decrease with an increasing level of care, but the effect of care is diminishing.

Activities of care are not costless. We assume that the costs of care can be depicted by a twice differentiable, increasing and convex function $c(\cdot)\left(c(0)=0 ; c^{\prime}(x)>0, c^{\prime \prime}(x) \geq 0 \forall x\right)$.

The preferences of injurer and victims are represented by utility functions with constant absolute risk aversion (CARA-utility functions). The risk aversion coefficients are $\alpha$ for the injurer and $\beta$ for the victims.

We concentrate on liability rules which stipulate a proportional sharing of losses. $q$ denotes the share of a (single) loss which has to be borne by the injurer $(0 \leq q \leq 1) .{ }^{5}$ The injurer's initial wealth is denoted by $W_{l}$ and each victim's (identical) initial wealth by $W_{V}$.

\section{The case without liability insurance}

First, suppose that there is no insurance coverage available for the injurer. The expected utility is expressed in terms of the certainty equivalent, which can be approximated by: 6

(2) $W_{l}+N-c(x)-n q E[L(x, Y)]-n^{2} \frac{\alpha}{2} q^{2} \sigma^{2}[L(x, Y)]$

for the injurer ${ }^{7}$ and

$$
W_{V}-(1-q) E[L(x, Y)]-\frac{\beta}{2}(1-q)^{2} \sigma^{2}[L(x, Y)]
$$

for a victim.

${ }^{5}$ Note that common liability rules can be assessed on the basis of this model, because efficiency of strict liability requires $q=1$ and the negligence rule requires $q=0$.

${ }^{6}$ See for example Pratt (1964), Sinn (1989, pp. 113 - 115), and Milgrom/Roberts (1992, p. 247). The approximation can be used if a decision maker's risk premium is small compared to the expected value of his wealth. For another justification of the $(\mu, \sigma)$ approach in liability theory see Holzheu (1994).

${ }^{7}$ Note that the injurer's risk premium depends strongly on the correlation between the victims' losses. As already mentioned, we assume that the losses are totally correlated. This assumption seems quite realistic for the analysis of many environmental risks, as for example the risk of harmful emissions. In other settings maybe it is more realistic to consider independent random variables $L_{i}\left(x, Y_{i}\right)$ $(i=1, \ldots, n)$. Under this assumption and if the losses are identically distributed $\left(L_{i}\left(x, Y_{i}\right) \sim L(x, Y) \forall i\right)$ the risk premium of the injurer is $n \frac{\alpha}{2} q^{2} \sigma^{2}[L(x, Y)]$. 


\subsection{First-Best-Optimum}

The FBO is an allocation that minimizes total cost resulting from the injurer's activities with respect to the injurer's level of care and his share of liability. Total cost is the sum of the cost of care, the expected value of losses and the risk premiums of victims and injurer. It can be approximated ${ }^{8}$ as:

(4) $\quad F(x, q):=c(x)+n E[L(x, Y)]+n^{2} \frac{\alpha}{2} q^{2} \sigma^{2}[L(x, Y)]+n \frac{\beta}{2}(1-q)^{2} \sigma^{2}[L(x, Y)]$.

We assume that an interior solution exists. It is characterized by:

$$
c^{\prime}(x)=-n E[L(x, Y)]_{x}-n^{2} \frac{\alpha}{2} q^{2} \sigma^{2}[L(x, Y)]_{x}-n \frac{\beta}{2}(1-q)^{2} \sigma^{2}[L(x, Y)]_{x} .
$$

The marginal cost of care equals the marginal return to care, which is the sum of a marginal decrease in the expected value of losses and a marginal reduction in the risk premiums. The optimal level of care in this model is therefore always higher than in a standard model without risk aversion.

The first-best-optimal injurer's liability share $q_{F B O}$ is:

(6) $q_{F B O}=\frac{\beta}{\beta+n \alpha}$.

With an increasing number of victims $q_{F B O}$ becomes smaller. Since the injurer's risk increases stronger than the total risk of all victims, implying that the monetary consequences of a loss for the injurer become relatively more important when $\mathrm{n}$ is increasing, the liability share that is optimal with respect to risk allocation has to be decreased. Furthermore, substituting $q_{F B O}$ from (6) into (5), we see that c.p. the right hand side in (5) grows with increasing $n$. So each increase in the number of victims results in a shift of the first-best-optimal amount of care to a higher level, because $q_{F B O}$ does not depend on $x$. This result, that - for example - a producer's optimal level of care grows when he is faced with an increasing number of claims due to one product failure, seems intuitively plausible.

The injurer will realize the maximum level of care if the number of potential victims is sufficiently large. ${ }^{9}$ Although his liability for the loss of each single victim diminishes, the quotient $n \beta /(\beta+n \alpha)$ grows larger. Therefore, the injurer's total liability cost rises, at least if the maximum care is reached.

Given the number of victims, $q_{F B O}$ depends on the risk aversion coefficients only and is strictly between zero and one, if injurer and victims are risk averters. The optimal liability share of the injurer (victim) decreases if c.p. his risk aversion coefficient increases. A tions.

${ }^{8}$ From now on we will not further mention that we use approximations of the relevant cost func-

${ }^{9}$ Ignoring the assumption that there is a maximum level of care, we derive, that the first-bestoptimal level of care tends to infinity, if we - just for analytical purposes - let $\mathrm{n}$ tend to infinity. To prove this, assume the statement is false. It follows that $x$ converges to an $x^{*}<\infty$ and $E[L(x, Y)]_{x}$ $\rightarrow E\left[L\left(x^{*}, Y\right)\right]_{x}$. Thus, the right hand side in (5) increases unboundedly while $c(x) \rightarrow c\left(x^{*}\right)$, which is not possible. 
solution which makes one party bear all the risk can only be optimal if - in contrast to the assumptions - at least one party is risk neutral. This result is well known from agencytheory. However, the consequences for optimal liability rules are almost completely neglected in the law and economics literature. Assume for a moment that courts are able to compute the standard of due care as characterized by (5). Then the FBO can be achieved by a combination of the negligence rule and a strict division of losses between injurer and victim: The injurer is liable $(q=1)$ if his level of care is less than due care. If the injurer exercises a level of care that equals or exceeds due care, his liability is determined by (6).

As in the literature on liability theory as well as in jurisdiction risk neutrality is the prevailing assumption, it is especially interesting to compute the welfare losses which result from the neglect of risk aversion. Since in the FBO courts have to establish a standard of due care, it is reasonable to discuss the welfare losses with respect to the negligence rule. Ignoring risk aversion, due care is determined by:

$$
\text { (7) } c^{\prime}(x)=-n E[L(x, Y)]_{x} \text {. }
$$

The marginal cost of care equals the marginal decrease in the expected value of losses. The injurer will exactly fulfill the standard of due care. Hence he will not be held liable $(q=0)$, which is an optimal solution if the victim is risk neutral. Considering risk aversion, this firstly results in a suboptimal risk allocation (compare (6)) and secondly the level of due care is set too low (compare (5)). Furthermore, since the injurer exercises the level of due care and is not held liable, the optimal level of care under the negligence rule is determined by:

$$
c^{\prime}(x)=-n E[L(x, Y)]_{x}-n \frac{\beta}{2} \sigma^{2}[L(x, Y)]_{x} .
$$

It is straightforward to see that the optimal level of care - given that $q=0$ - is even larger than in the FBO where risk aversion is considered in setting the standard of due care, because of the inefficient risk allocation. Thus, disregarding risk aversion results in serious inefficiencies: The risk allocation is suboptimal and the standard of due care is too low. The last problem becomes even worse, since the optimal level of care, given the suboptimal risk allocation $(q=0)$, is higher than under optimal risk allocation.

However, the welfare losses of the negligence rule decrease with an increasing number of victims. With a sufficiently large number of victims, the injurer will realize the maximum level of care even if due care is determined by (7). Since the optimal liability share of the injurer decreases with an increasing number of victims, the difference between the negligence rule and the FBO becomes smaller.

So far it has been implicitely assumed that the FBO can be reached. But one cannot expect that courts are able to determine the first-best-optimal level of care and the first-

\footnotetext{
${ }^{9}$ Ignoring the assumption that there is a maximum level of eare, we derive, that the first-bestoptimal level of care tends to infinity, if we - just for analytical purposes - let $\mathrm{n}$ tend to infinity. To prove this, assume the statement is false. It follows that $x$ converges to an $x^{*}<\infty$ and $\left.E / L(x, Y)\right]_{x}$ $\rightarrow E\left[L\left(x^{*}, Y\right)\right]_{x}$. Thus, the right hand side in (5) increases unboundedly while $c(x) \rightarrow c\left(x^{*}\right)$, which is not possible.
} 
best-optimal risk sharing, because to do so they have to know the risk aversion coefficients of the parties. The assumption that courts can observe risk aversion is undoubtedly very unrealistic: Both parties have an incentive not to reveal their degree of risk aversion honestly, as their share in liability will be the lower the higher their risk aversion is assumed to be. Furthermore, the level of due care depends on the degree of risk aversion of the victims, which is normally not known by the injurer. The FBO would thus imply uncertainty of the injurer concerning the standard of due care. Therefore, a process during which the courts try to determine the risk aversion of the parties and due care and optimal liability depending on it, is not a realistic option.

Nevertheless, it does not follow that the courts have to neglect risk aversion completely. They could alternatively use average risk aversion coefficients. If the injurer is, for example, a public limited company, and the victims are individuals, the average risk aversion coefficients of individuals and managers of public limited companies would be adequate estimations of the «true» risk aversion.

Average risk aversion coefficients would have to be estimated, too, but this is a solvable problem if we take into consideration for example the insurance demand decisions of the respective groups. If, for example, courts imply a very cautious estimation of the victims' risk aversion coefficient - that is, if they favor a lower estimation over a higher estimation - we get an increase in welfare compared to the complete neglect of risk aversion: The liability rule comes closer to the FBO, as the level of due care is increased and the victims optimal liability is decreased.

\subsection{Second-Best-Optimum}

The determination of due care causes a number of problems. The wrong determination of due care by the courts and an incorrect anticipation of due care by the injurers are only two examples for such problems. If these problems become too large, no due care should be determined. Without such a standard the optimal level of care and the optimal risk allocation cannot - as in the FBO - be reached simultaneously. The injurer's share of liability controls risk allocation and induces the level of care. Thus, an «optimal compromise» has to be found between these two conflicting goals.

To determine the SBO, we first look at the decision about the optimal level of care: For a given level of $q$ the injurer decides upon his level of care by minimizing the following cost function $\left(F_{i n j}\right)$ :

(9) $\quad F_{i n j}(x):=c(x)+n q E[L(x, Y)]+n^{2} \frac{\alpha}{2} q^{2} \sigma^{2}[L(x, Y)]$,

leading to the first order condition for an interior solution

$$
c^{\prime}(x):=-n q E[L(x, Y)]_{x}-n^{2} \frac{\alpha}{2} q^{2} \sigma^{2}[L(x, Y)]_{x} .
$$

Comparing (5) and (10) it follows that under these conditions the injurer will take less care than in the FBO, if his share of liability is $q_{F B O}$. Furthermore his optimal level of 
care is an increasing function of $q: x=x(q)$ with $x^{\prime}(q)>0$ (if $0<x(q)<x_{\max }$ ). We can determine second-best-optimal liability by minimizing the following function with respect to $q$ :

$$
F(q):=c(x(q))+n E[L(x(q), Y)]+n^{2} \frac{\alpha}{2} q^{2} \sigma^{2}[L(x(q), Y)]+n \frac{\beta}{2}(1-q)^{2} \sigma^{2}[L(x(q), Y)] .
$$

Proposition 1: If $x(q)>0$ for each $q>0$ and $c^{\prime}(0)<-n E[L(0, Y)]_{x}$, the second-best-optimal liability share of the injurer $q_{S B O}$ (for a given number of victims) is larger than (or at least as large as) $q_{F B O}$.

$$
\begin{array}{ll}
\text { In particular: a) } & 1>q_{S B O}>q_{F B O}, \text { if } x\left(q_{F B O}\right)<x_{\max } \text { and } \\
\text { b) } & 1>q_{S B O}=q_{F B O} \text {, if } x\left(q_{F B O}\right)=x_{\max }
\end{array}
$$

Proof: see appendix.

The intuition behind this result is fairly clear, because in the SBO the liability share controls the risk allocation as well as the level of care. If the first-best-optimal liability share of the injurer is large enough to induce the maximum level of care, this level of liability is also second-best-optimal. There would not be any additional incentive effects from a share of liability that exceeds $q_{F B O}$. But if $q_{F B O}$ does not induce the maximum care, additional incentives are necessary to reach the SBO.

Given a strictly positive share of liability $q$, the maximum level of care is induced for a sufficiently large $\mathrm{n}$. Thus we can derive the important result, that - dealing with large numbers $n$ - it is always possible to approximately reach the FBO by fixing a $q$ that is small, but sufficiently large to induce the maximum level of care.

As in the preceeding section, we will now ask what welfare losses will result if courts neglect risk aversion in deciding about the injurer's share in liability. As already mentioned, the SBO will be used as a point of reference for situations in which the problems concerning the determination of an optimal level of due care are too severe. Hence it is reasonable to discuss the consequences of neglecting risk aversion with respect to liability rules without implementation of due care. Since we are concerned with unilateral losses only, strict liability becomes optimal if risk aversion is ignored. Therefore the SBO is compared with strict liability: Strict liability results in a suboptimal risk allocation, as optimal risk allocation in SBO implies a strict division of liability. Furthermore, because of the suboptimal risk allocation, the injurer chooses a level of care which is higher than in FBO and SBO. This is a remarkable result, as the level of care is set too low under the negligence rule.

Welfare losses due to strict liability become very serious if the number of victims is large: Second-best-optimal risk allocation implies that the injurer is liable for only a small fraction of total losses, but under strict liability he is fully liable. It was already shown that welfare losses under the negligence rule decrease with an increasing number of victims. Therefore, if courts are not able to take risk aversion into consideration, with an increasing number of victims the implementation of a negligence rule becomes c.p. more preferable compared to strict liability.

For the case of one victim the main results so far are quite well known from literature. Especially see Shavell (1982) and Shavell (1987), pp. 218 -222, who shows that if risk 
aversion is taken into account and if there is no standard of due care, Pareto optimal liability of an injurer has to be less than the losses, which means in our context that the injurer's optimal liability share in the SBO has to be smaller than one. Furthermore Shavell shows that under the negligence rule in a Pareto optimal solution for risk averse parties the standard of due care is different from the level that would be optimal in the case of risk neutrality.

\section{The case with liability insurance}

We now include the availability of liability insurance for the injurer. It is assumed that any proportion $d$ of insurance coverage can be bought. Furthermore, we assume that the insurer has complete information about the expected value of losses which might result from the activities which are to be insured, so that moral hazard as well as adverse selection problems are excluded. The premium is calculated by adding a proportional loading $m$ to the expected value of losses. Thus the insurance premium $P$ is:

$$
P=n(1+m) d q E[L(x, Y)]
$$

For technical reasons we assume that the loading $m$ will not exceed a certain upper limit. For each level of care condition (13) shall be valid:

$$
\text { (13) } \beta \sigma^{2}[L(x, Y)]>m E[L(x, Y)] \text {. }
$$

This assumption is not very restrictive, because the variance of realistic loss distributions usually is much larger than the expected value of losses.

\subsection{First-Best-Optimum}

Total cost has to be minimized with respect to insurance coverage, liability and the level of care:

$$
\begin{aligned}
F(x, q, d):= & c(x)+n(1+m d) q E[L(x, Y)]+n^{2} \frac{\alpha}{2}(1-d)^{2} q^{2} \sigma^{2}[L(x, Y)] \\
& +n \frac{\beta}{2}(1-q)^{2} \sigma^{2}[L(x, Y)]+n(1-q) E[L(x, Y)] .
\end{aligned}
$$

Let $x_{F B O}^{I}, q_{F B O}^{I}$ and $d_{F B O}^{I}$ denote the solution.

The first-best-optimal demand for insurance is: ${ }^{10}$

$$
d_{F B O}^{I}=1-\frac{m E\left[L\left(x_{F B O}^{I}, Y\right)\right]}{\alpha n q_{F B O}^{I} \sigma^{2}\left[L\left(x_{F B O}^{I}, Y\right)\right]}
$$

19 The quotient in (15) always exists, because $q_{F B O}^{I}$ is positive. To prove this we assume that $q_{F B O}^{I}$ equals zero. Since by setting $d_{F B O}^{l}=0$ we can reach every level of total cost that is available in the case without insurance and since for $q_{F B O}^{I}=0$ respectively $q_{F B O}=0$ total cost is the same in both cases, $q_{F B O}$ also has to be zero. As we have seen this is not possible. 
The demand for insurance increases c.p. with increasing $n$, increasing risk aversion coefficient $\alpha$, increasing liability, decreasing loading and increasing ratio of variance and expected value of losses.

For a comparison with the case without insurance we look at

$$
q_{F B O}^{l}=1-\frac{\beta}{\beta+\alpha n\left(1-d_{F B O}^{l}\right)},
$$

which follows from the first order conditions. ${ }^{11}$ If insurance coverage is available, the optimal liability of the injurer is increased. The higher the insurance coverage, the higher the liability. C.p. $d_{F B O}^{l}$ depends on the loading $m$. Thus, in the FBO the liability of the injurer is the higher the cheaper the insurance is. Only if $\mathrm{m}$ becomes zero, that is in the extreme case of a fair premium, strict liability becomes first-best-optimal.

Substituting $d_{F B O}^{I}$ from (15) into (16) we obtain:

$$
q_{F B O}^{I}=1-\frac{m E\left[L\left(x_{F B O}^{I}, Y\right)\right]}{\beta \sigma^{2}\left[L\left(x_{F B O}^{I}, Y\right)\right]}
$$

Thus, in contrast to the situation without insurance, the injurer's liability will not be smaller than $\underline{q}^{12}$

The first-best-optimal level of care is characterized by:

$$
c^{\prime}(x)=-n(1+m d q) E[L(x, Y)]_{x}-n^{2} \frac{\alpha}{2}(1-d)^{2} q^{2} \sigma^{2}[L(x, Y)]_{x}-n \frac{\beta}{2}(1-q)^{2} \sigma^{2}[L(x, Y)]_{x} .
$$

It is ambiguous whether the optimal level of care in the FBO with liability insurance is higher or lower than in the FBO without insurance coverage. But the lower the loading is, the more likely the optimal level of care with liability insurance decreases. If $m$ becomes zero, there are no risk premiums and the optimal level of care is the same as in standard theory.

Since we have derived the FBO, the inefficiencies of ignoring risk aversion are again discussed with respect to the negligence rule. There is an ambiguous relation between the magnitude of the loading and welfare losses: On the one hand, the smaller the loading, the smaller the difference between the first-best-optimal level of care and the standard of due care set by courts. On the other hand, the smaller the loading, the higher the injurer's optimal share in liability and the worse the risk allocation under the negligence rule.

Without liability insurance welfare losses under the negligence rule are small when the number of victims is large. With liability insurance this is clearly not the case, since the

$11 \mathrm{We}$ assume the loading factor to be sufficiently small to ensure that $d_{F B O}^{l}$ is nonnegative. This is possible without technical complications, because from (15), (16) and (13) we learn:

$q_{F B O}^{l} \geq \underline{q}=1-\max _{x}\left[\frac{m E[L(x, Y)]}{\beta \sigma^{2}[L(x, Y)]}\right]>0$

12 See footnote 11 . 
injurer's optimal share of liability will in general not be close to zero as is shown by (17). This is because the injurer can transfer his risk to insurance companies at a fixed price $m$ and therefore there is no strong increase in his risk premium due to an increasing number of victims. For that reason even in the case of many victims, substantial welfare improvements can be attained by using average risk aversion coefficients as discussed above. With liability insurance there is an additional advantage for this proceeding. The risk aversion coefficient of the injurer is needed for the determination of due care but not for optimal risk sharing. Consequently the effects of the inaccuracy resulting from the estimation of the risk aversion coefficients are reduced.

\subsection{Second-Best-Optimum}

Not considering the victims' cost, an injurer minimizes:

$$
F_{i n j}(x, d):=c(x)+n(1+m d) q E[L(x, Y)]+n^{2} \frac{\alpha}{2}(1-d)^{2} q^{2} \sigma^{2}[L(x, Y)]
$$

Let $x_{S B O}^{I}, q_{S B O}^{I}$ and $d_{S B O}^{I}$ denote the SBO. $q_{S B O}^{I}$ has to be positive ${ }^{13}$ and we get:

$$
d_{S B O}^{l}=1-\frac{m E\left[L\left(x_{S B O}^{I}, Y\right)\right]}{\alpha n q_{S B O}^{I} \sigma^{2}\left[L\left(x_{S B O}^{I}, Y\right)\right]} .
$$

One would expect that in the SBO the injurer's share of liability increases compared to the FBO, as in the case of no insurance. But formal analysis shows that this expectation is fulfilled under specific conditions only:

Proposition 2: If each $q>0$ induces a positive level of care, $c^{\prime}(0)<-n E[L(0, Y)]_{x}$, and under the additional assumption that the quotient $E^{2}[L(x, Y)] / \sigma^{2}[L(x, Y)]$ is constant or increasing in $x$ with decreasing increments, the results of proposition 1 are valid also in the case of available liability insurance, which means that (for a given $n$ )

$$
\begin{aligned}
& \text { a) } 1>q_{S B O}^{I}>q_{F B O}^{l} \text {, if } x^{I}\left(q_{F B O}^{I}\right)<x_{\max } \text { and } \\
& \text { b) } 1>q_{S B O}^{I}=q_{F B O}^{I} \text {, if } x^{I}\left(q_{F B O}^{I}\right)=x_{\max },
\end{aligned}
$$

where $x^{J}(q)$ is the level of care, that minimizes $F_{i n j}$ for a given share of liability $q$.

Proof: see appendix.

Thus, as in the FBO in the SBO the liability of the injurer will always be larger than $q$ when the number of victims increases. Therefore it follows that $x_{S B O}^{l}$ reaches the maximum level of care for a sufficiently large $n$, too.

A valuable result can be derived by considering a situation where the number of potential victims is large enough that the injurer chooses the maximum level of care for each $q \geq q$. Then we can achieve the FBO allocation by setting the injurer's liability first-

${ }^{13}$ See footnote 10. 
best-optimal. Again the foundation of this result is that the maximum level of care is reached anyway and hence only optimal risk sharing has to be taken into account.

Strict liability causes suboptimal risk allocation since $q_{S_{B} O}^{I}$ has to be less than one. Furthermore the injurer takes too much care under strict liability unless the maximum level of care is reached in the SBO. As the FBO can be achieved if the number of victims is large enough, it is also of interest to compare this solution to the negligence rule: Ignoring risk aversion under the negligence rule would result in a suboptimal risk allocation, as the optimal share in liability of the injurer will in general not be close to zero. Therefore the use of cautiously calculated average risk aversion coefficients can clearly improve the results in comparison with strict liability as well as the negligence rule.

\section{Concluding comments}

Some main results of standard liability theory are no longer valid if two basic assumptions are changed: Assuming risk averse individuals and insurance coverage which is available at a loading on the expected value of losses only, no liability rule with full liability of one party is first-best- or second-best-optimal. Strict liability, no liability and the negligence rule are all suboptimal. First-best- or second-best-optimal liability rules have to stipulate a strict division of accident losses between injurer and victim.

If a standard of due care cannot be established without too severe difficulties, liability has to control the level of care besides the risk allocation. It has been shown that the injurer's part of liability is larger in the SBO than in the FBO, unless the risk is that large that even the first-best-optimal liability would induce the maximum care. Under the latter conditions there is no difference between FBO and SBO. For example the maximum level of care will be reached in any case, if c.p. the number of potential victims is sufficiently large.

The optimal liability sharing depends on the availability of insurance coverage. We get an important result for the situation in which the number of victims is large: While the injurer's liability is close to zero in the case of no insurance coverage, it does not become smaller than a positive lower boundary if he can insure and if we assume realistic loss distributions.

The neglect of risk aversion causes inefficiencies of risk allocation and taking care. To analyse the differences between the optimal solutions presented in this article and the results without risk aversion, we have compared the FBO to the negligence rule and the SBO to strict liability. We have seen that in the case of no insurance for large numbers of victims the inefficiencies of ignoring risk aversion by establishing a negligence rule would be less strong than by using strict liability. If insurance coverage is available, this result does not hold in general, because the injurer's liability does not tend to zero.

These results demonstrate that the number of victims has to be taken into account when optimal liability rules are determined, a subject that was ignored in literature on liability theory until now. 
Obviously, central statements of liability theory hinge upon the assumptions made. Concluding the paper, we will therefore briefly discuss some modifications of our assumptions:

- We considered unilateral losses only, which is realistic for the analysis of environmental accidents, but not for general liability theory. However, we do not expect substantial changes of our results for bilateral accidents: Optimal liability will still imply a strict division of losses, but the victim's fraction of liability will probably increase in the SBO.

- Insurance coverage for the victims has been neglected; but first-party-insurance that is available at a loading only will not essentially modify the basic results.

- The assumption that the loading solely depends on the expected losses is undoubtedly very restrictive: In reality, liability insurance losses might become very large. For that reason a more realistic assumption would be that insurers are risk averse against such losses, and will therefore calculate their premiums with reference to a risk measure, for example on the basis of the variance principle. ${ }^{14} \mathrm{~A}$ change of the premium principle will probably lead to different results: As insurance premiums would then increase quadratically in the number of victims, the optimal liability share of the injurer would become very small (as in the case without insurance).

- The only insurance form we considered is coinsurance. Analysis of other forms of risk sharing between insured and insurer, for example deductibles, is technically rather difficult and we cannot yet assess whether and how the results would change.

- The judgment proof problem has not been tackled. Considering it, the problem of suboptimal demand for insurance emerges: because the injurer calculates his demand for insurance on the basis of a loss distribution which is cut off at the magnitude of the loss which results in his inability to pay, but not on the basis of the true loss distribution, he demands less insurance coverage. It seems reasonable to tackle this problem by regulating insurance demand, for example by compulsory insurance (see for instance Shavell (1986)). But compulsory insurance can be integrated in our model without any problems and would not change results substantially.

- The activity level of the injurer was treated as exogenously given, while in standard theory some results concerning the optimal level of activity have already been derived (see for example Shavell (1980)). These results cannot be easily transferred to a situation with risk averse parties and loaded insurance premiums. Thus an important topic of future investigation is the determination of optimal liability under consideration of insurance demand, level of care and level of activity.

${ }^{14}$ For a discussion of different premium principles see e.g. Heilmann (1988), pp. 150-185. 


\section{Appendix}

Proposition 1: If $x(q)>0$ for each $q>0$ and $c^{\prime}(0)<-n E[L(0, Y)]_{x}$, the second-best-optimal liability share of the injurer $q_{S B O}$ (for a given number of victims) is larger than (or at least as large as) $q_{F B O}$.

In particular: a) $\quad 1>q_{S B O}>q_{F B O}$, if $x\left(q_{F B O}\right)<x_{\max }$ and

b) $\quad 1>q_{S B O}=q_{F B O}$, if $x\left(q_{F B O}\right)=x_{\max }$.

Proof:

First, we prove $q_{S B O}>0$ : Consider the function of total cost

$$
F(q):=c(x(q))+n E[L(x(q), Y)]+\left(n^{2} \frac{\alpha}{2} q^{2}+n \frac{\beta}{2}(1-q)^{2}\right) \sigma^{2}[L(x(q), Y)] .
$$

Since $x(\theta)=0, c^{\prime}(0)<-n E[L(0, Y)]_{x}, \sigma^{2}[L(0, Y)]_{x}<0$ and

$$
\left.\frac{d}{d q}\left(n^{2} \frac{\alpha}{2} q^{2}+n \frac{\beta}{2}(1-q)^{2}\right)\right|_{q=0}=-n \beta<0,
$$

starting from $q=0$ a marginal increase of $q$ will result in a decrease of total costs. Therefore $q_{S B O}$ has to be larger than zero.

Suppose $q_{S B O}<1$. First we consider the case $x\left(q_{F B O}\right)<x_{\max }$. If $x\left(q_{S B O}\right)=x_{\max }$, there is nothing left to show. If $x\left(q_{S B O}\right)<x_{\max }, q_{S B O}$ solves the following first order condition:

$$
\begin{aligned}
& \left.F^{\prime}(q)=c^{\prime}(x(q))+n q E[L(x(q), Y)]_{x}+n^{2} \frac{\alpha}{2} q^{2} \sigma^{2}[L(x(q), Y)]_{x}\right] x^{\prime}(q) \\
& +[n \alpha q-\beta(1-q)] n \sigma^{2}[L(x(q), Y)] \\
& \left.+n \frac{\beta}{2}(1-q)^{2} \sigma^{2}[L(x(q), Y)]_{x}+n(1-q) E[L(x(q), Y)]_{x}\right] x^{\prime}(q)=0 .
\end{aligned}
$$

The first term always equals zero, because the term in the brackets represents the first order condition for optimal care. The third term in (23) is negative, which implies the second term being positive and therefore $q_{S B O}>\beta /(n \alpha+\beta)=q_{F B O}$.

Now consider the case $x\left(q_{F B O}\right)=x_{\max }$ :

Let $x_{F B O}(q)$ denote the level of care that minimizes total cost for a given share of liability $q(x(q)$ is the level of care that minimizes the injurer's cost). As for a given $q$ the victims' cost decreases with an increasing level of care, we see that $x_{F B O}(q) \geq x(q)$. Therefore, if $x\left(q_{F B O}\right)=x_{\max }$, the maximum level of care is first-best-optimal and $q_{S B O}=q_{F B O}$.

To finish the proof we have to show $q_{S B O}<1$ :

Assume $q_{S B O}=1:$ 1. $x\left(q_{S B O}\right)<x_{\max }:$ From (23) follows $\lim _{q \uparrow_{1}} F^{\prime}(q)>0$ in contradiction to the assumption.

2. $x\left(q_{S B O}\right)=x_{\max }$

2.1. $\quad q_{S B O}>q^{*}:=\inf \left(q: x(q)=x_{\text {max }}\right\} \Rightarrow q_{S B O}=q_{F B O}<1$ (from $F^{\prime}\left(q_{S B O}\right)=$ $\left.\left[n \alpha q_{S B O^{-}} \beta\left(1-q_{S B O}\right)\right] n \sigma^{2}\left[L\left(x_{\max }, Y\right)\right]=0\right)$ in contradiction to $q_{S B O}=1$. 
2.2. $q_{S B O}=q^{*}$ : Since $x^{\prime}(q)$ is limited, from (23) we see that $\lim _{q \uparrow l} F^{\prime}(q)>0$ in contradiction to $q_{S B O}=1$.

q.e.d.

Proposition 2: If each $q>0$ induces a positive level of care, $c^{\prime}(0)<-n E[L(0, Y)]_{x}$, and under the additional assumption that the quotient $E^{2}[L(x, Y)] / \sigma^{2}[L(x, Y)]$ is constant or increasing in $x$ with decreasing increments, the results of proposition 1 are valid also in the case of available liability insurance, which means that (for a given $n$ )

a) $1>q_{S B O}^{I}>q_{F B O}^{I}$, if $x^{I}\left(q_{F B O}^{I}\right)<x_{\max }$ and

b) $1>q_{S B O}^{l}>q_{F B O}^{l}$, if $x^{I}\left(q_{F B O}^{I}\right)<x_{\max }$,

where $x^{I}(q)$ is the level of care, that minimizes $F_{i n j}$ for a given share of liability $q$.

Proof:

After substituting $d_{S B O}^{l}$ from (20) in (19), the injurer's cost function for a given $q$ reads

$$
F_{i n j}(x):=c(x)+n(1+m) q E[L(x, Y)]-\frac{m^{2} E^{2}[L(x, Y)]}{2 \alpha \bar{\sigma}^{2}[L(x, Y)]}
$$

The assumption concerning the ratio of expected value and standard deviation ensures that $x^{I}(q)$ is unique and increasing. Considering that $E^{2}[L(x, Y)] / \sigma 2[L(x, Y)]$ is increasing means that the coefficient of variation is decreasing, this assumption is not too restrictive.

The second-best-optimal liability rule is represented by the level of $q$ which minimizes

$$
\begin{aligned}
F(q) & :=c\left(x^{I}(q)\right)+n(1+m) q E\left[L\left(x^{I}(q), Y\right)\right]-\frac{m^{2} E^{2}\left[L\left(x^{I}(q), Y\right)\right]}{2 \alpha \sigma^{2}\left[L\left(x^{I}(q), Y\right)\right]} \\
& +n \frac{\beta}{2}(1-q)^{2} \sigma^{2}\left[L\left(x^{I}(q), Y\right)\right]+n(1-q) E\left[L\left(x^{I}(q), Y\right)\right] .
\end{aligned}
$$

As in the proof of proposition 1 we see that $q_{S B O}^{I}$ is positive.

Suppose $q_{S B O}^{I}<1$. Again, first we consider the case $x^{I}\left(q_{F B O}^{I}\right)<x_{\max }$. If $x^{I}\left(q_{S B O}^{I}\right)=x_{\max }$, there is nothing to prove. Therefore, assume $x^{I}\left(q_{S B O}^{I}\right)<x_{\max }$. Under the assumptions made the function $x^{I}(q)$ is differentiable with $d x^{I}(q) / d q>0$ if $0<x^{I}(q)<x_{\max }$, and the SBO is a solution of:

$$
\begin{aligned}
F^{\prime}(q)= & {\left[c^{\prime}\left(x^{I}(q)\right)+n(1+m) q E\left[L\left(x^{I}(q), Y\right)\right]_{x}-\frac{m^{2}}{2 \alpha}\left[\frac{E^{2}\left[L\left(x^{I}(q), Y\right)\right]}{\sigma^{2}\left[L\left(x^{I}(q), Y\right)\right]}\right]_{x}\right] \frac{d x^{I}(q)}{d q} } \\
& +n m E\left[L\left(x^{I}(q), Y\right)\right]-n \beta(1-q) \sigma^{2}\left[L\left(x^{I}(q), Y\right)\right] \\
& +\left[n \frac{\beta}{2}(1-q)^{2} \sigma^{2}\left[L\left(x^{I}(q), Y\right)\right]_{x}+n(1-q) E\left[L\left(x^{I}(q), Y\right)\right]_{x}\right] \frac{d x^{I}(q)}{d q}=0 .
\end{aligned}
$$


As the same connection between the level of care and the insurance coverage (given $q$ ) exists in the FBO and in the SBO, we can directly compare the optimal liability levels. To achieve this comparison, we substitute for $d$ in the total cost function of the FBO analysis. We denote as $x_{F B O}^{I}(q)$ the level of care, which minimizes this function for any given $q$. For each $q$, it follows that $x^{I}(q) \leq x_{F B O}^{I}(q)$, because the victims' cost decreases in $x$ for any given liability. $x_{F B O}^{L}(q)$ increases in $q$, too.

A closer look at (26) reveals

$$
q_{S B O}^{I}>1-\frac{m E\left[L\left(x^{I}\left(q_{S B O}^{I}\right), Y\right)\right]}{\beta \sigma^{2}\left[L\left(x^{I}\left(q_{S B O}^{I}\right), Y\right)\right]}
$$

while in the FBO we get equality according to (17). Thus, since from $\left[\begin{array}{l}E^{2}[L(x, Y)] \\ \sigma^{2}[L(x, Y)]\end{array}\right] \geq 0$ follows $\left[\frac{E[L(x, Y)]}{\sigma^{2}[L(x, Y)]}\right]_{x} \geq 0$ and because $x^{I}(q) \leq x_{F B O}^{l}(q)$, we get

$$
q_{S B O}^{I}>1-\frac{m E\left[L\left(x_{F B O}^{l}\left(q_{S B O}^{l}\right), Y\right)\right]}{\beta \sigma^{2}\left[L\left(x_{F B O}^{l}\left(q_{S B O}^{l}\right), Y\right)\right]}
$$

Note, that the right hand side increases with a decreasing level of $q$. So we have to reduce $q$ to reach equality and thus the FBO. This means $q_{S B O}^{I}>q_{F B O}^{l}$.

As we have already seen that for each $q x^{I}(q) \leq x_{F B O}$, the remaining case $x^{I}\left(q_{F B O}^{l}\right)=x_{\max }$ can be analysed exactly as in the proof of proposition 1 . Furthermore the proof of $q_{S B O}^{I}<1$ is very similar to the proof of $q_{S B O}<1$.

q.e.d. 


\section{REFERENCES}

ADAMS, M. (1985): Ökonomische Analyse der Gefährdungs- und Verschuldenshaftung, Heidelberg.

ARLEN, J. H. (1992): Should Defendants' Wealth Matter?, Journal of Legal Studies, 21, 413 - 429.

BROWN, J. P. (1973): Toward an Economic Theory of Liability, Journal of Legal Studies, 2, 323 349.

CALABRESI, G. (1961): Some Thoughts on Risk Distribution and the Law of Torts, Yale Law Journal, 70, $499-553$.

ENDRES, A. (1991): Ökonomische Grundlagen des Haftungsrechts, Heidelberg.

GRACE, M. F. and REBELLO, M. J. (1993): Financing and the Demand for Corporate Insurance, The Geneva Papers on Risk and Insurance Theory, 18, 147-172.

GREEN, J. (1976): On the Optimal Structure of Liability Laws, Bell Journal of Economics, 7, 553 574.

HEILMANN, W. R. (1988): Fundamentals of Risk Theory, Karisruhe.

HOLZHEU, T. (1994): Umweltpolitik durch Haftungsregeln, Munich.

LANDES, W. M. and POSNER, A. (1987): The Economic Structure of Tort Law, Cambridge (Mass.).

MILGROM, P. and ROBERTS, J. (1992): Economics, Organization and Management, Englewood Cliffs (New Jersey).

NELL, M. and TRAUB, W. (1994): Die Haftung von Versicherungsmaklern als ökonomisches Problem, ZVersWiss, 83, 93 - 112.

PRATT, J. W. (1964): Risk Aversion in the Small and in the Large, Econometrica, 32, 122 - 136.

SHAVELL, S. (1980): Strict Liability versus Negligence, Journal of Legal Studies, 9, 1 - 25.

SHAVELL, S. (1982): On Liability and Insurance, Bell Journal of Economics, 13, 120 - 132.

SHAVELL, S. (1986): The Judgment Proof Problem, International Review of Law and Economics, 6, $45-58$.

SHAVELL, S. (1987): Economic Analysis of Accident Law, Cambridge (Mass.).

SINN, H. W. (1989): Economic Decisions Under Uncertainty, 2. ed., Heidelberg.

TILLINGHAST (1990): Cost of Risk Survey, Darrien (Conn.).

TIROLE, J (1990): The Theory of Industrial Organization, Cambridge (Mass.).

TRAUB, W. and NELL, M. (1993): The Liability of Insurance Brokers as a Principal-Agent-Problem, C. Hipp et al. (ed.): Geld, Finanzwirtschaft, Banken und Versicherungen, Karlsruhe, 725 - 735. 